\title{
Liquid Chromatographic Methods for Anti-tubercular Agents: An Overview
}

\author{
Deepika Bairagee ${ }^{1}$
}

\author{
${ }^{1}$ Oriental College of Pharmacy and Research, Oriental University, Indore, Madhya \\ Pradesh, India
}

\begin{abstract}
The aim of this review is to summarise the different analytical and bioanalytical methods used to determine the concentration of anti-tubercular agents from last few years. As we know that tuberculosis is a life threatening disease and second to HIV in terms of deaths due to infectious diseases. Drug resistance development of the first-line drugs is a most important concern in the cure of this disease. There is no comprehensive and critical review in the literature for the analytical and bioanalytical methods for the determination of ant-tubercular agents from last few years. So this work provides the detailed account on the chromatographic methods reported in the literature for the estimation of various ant-tubercular drugs.
\end{abstract}

Keywords : Anti-tubercular drugs; Chromatographic methods; Bioanalytical methods; Estimation; Concentration.

\section{Introduction:}

Tuberculosis is one of the oldest main killers between infectious diseases since ancient times. There have been several reports on TB from different parts of the world among various civilizations. Mycobacterium tuberculosis, is the caustive agent behind $\mathrm{TB}^{1,2}$. Two major forms of $\mathrm{TB}$ have been known on the basis of site of infection, called as Pulmonary Tuberculosis (PTB) and Extra Pulmonary Tuberculosis (EPTB). Pulmonary TB is the most common form of the disease and constitutes about $85 \%$ of all TB cases ${ }^{3,4}$.

Mycobacterium tuberculosis is carried in airborne particles, called droplet nuclei, of 1-5 microns in diameter and is transmitted when a perosn with active TB disease of the lungs or throat cough/sneezes ${ }^{5}$. People nearby may breathe-in these bacteria and become infected. Human beings are infected through the respiratory tract and the tubercle bacilli spreads by lymphatic system and blood stream to different organs. the course of tubercular disease is divided into primaty pulmoanry TB, latent TB infection and acitve TB disease, including tuberculo-meningitis, skin TB, scrofulous TB, pleurisy TB, cordis TB, urinary systemic TB, digestive systemic TB, skeletal TB, etc ${ }^{6-9}$. People with active TB disease can e treated and cured if they seek medical help. Even better, people with latent TB infection can take medicine so that they will not develop active TB disease ${ }^{10}$. Various targets were explored for antitubercular drug discoveries, recently explored DprE1 is one of them ${ }^{11-14}$. Few analogues of DprE1 inhibitors are inder pre clinical trials ${ }^{15}$. 
People having active tuberculosis disease develop symtoms, like cough, which propels the bacteria into air, where these bacilli can be inhaled by others. Therfore, TB must be diagnosed and treated as soon as possible to render the person non-infectious and prevent the spread of the disease. The most common methods to diagonise tuberclosis is a simple skin test, though blood tests are becoming more commonplace. A small amount of a substance called PPD tuberculin is injected just below the skin of your inside forearm. You should feel only a slight niddle prick. Within 48-72 hours, a health care professional will check your arm for swelling at the injectin site. A hard, raised red bump means, you are likly to have TB infectio. The size of the bump determines whether the test results are significant ${ }^{16}$.

The first line drugs are used in the treatmet of new TB cases in which the risk of resistance is low or negligible and usually are given orally, while the second line drugs are used to treat cases, whihc are resistnat to first line drugs. The second line drugs can be further categorized into 4 subgroups, viz, injectable second lne drugs, fluoroquinolones, oral bacteriostatic anti-TB agents and anti-tuberculosis agents. The main first line drugs used are Isoniazid, Rifampicin, Ethambutal and Streptomycin ${ }^{\mathbf{7}-19}$.

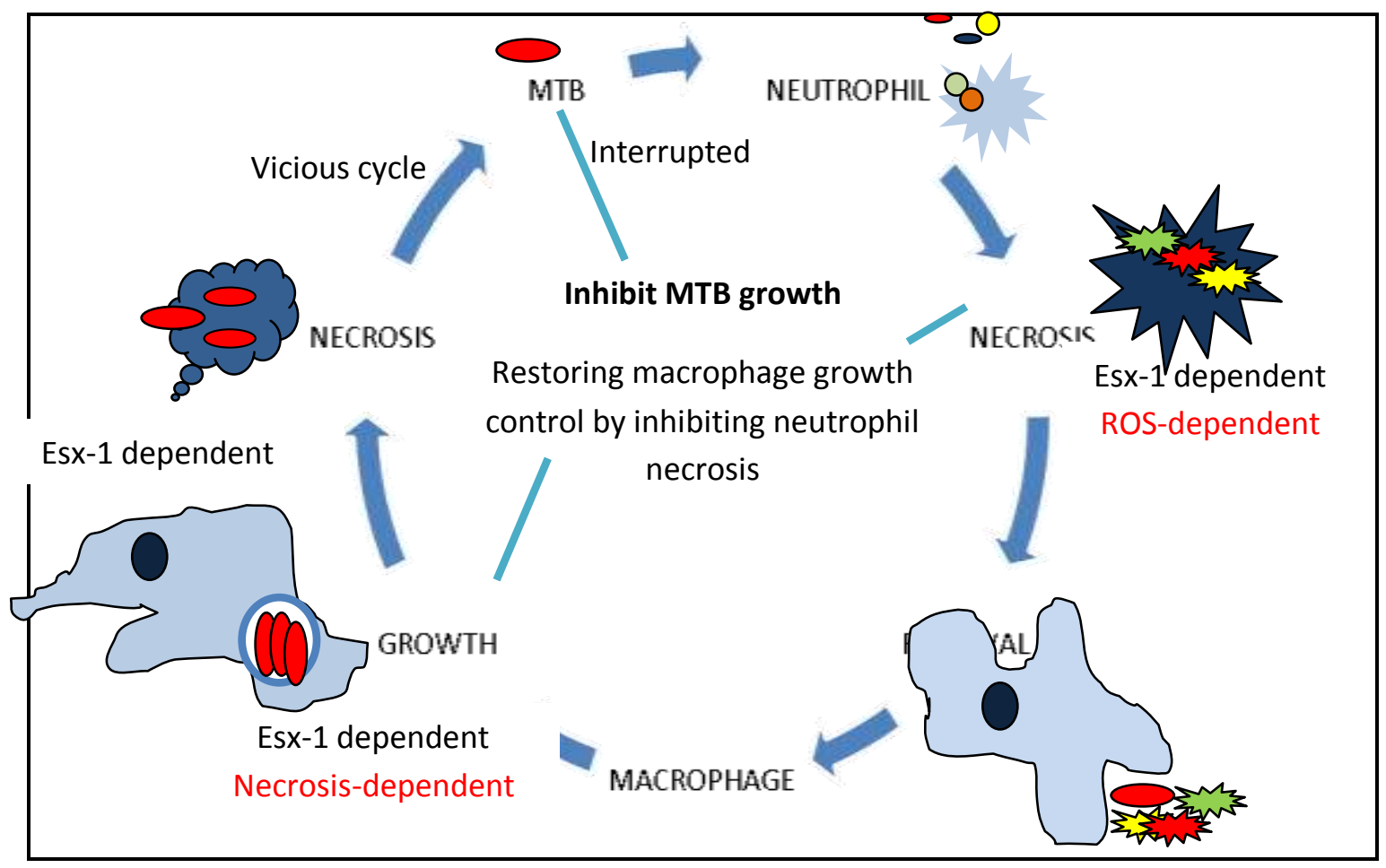

Fig. 1. The vicious circle of host cell necrosis during MTB 


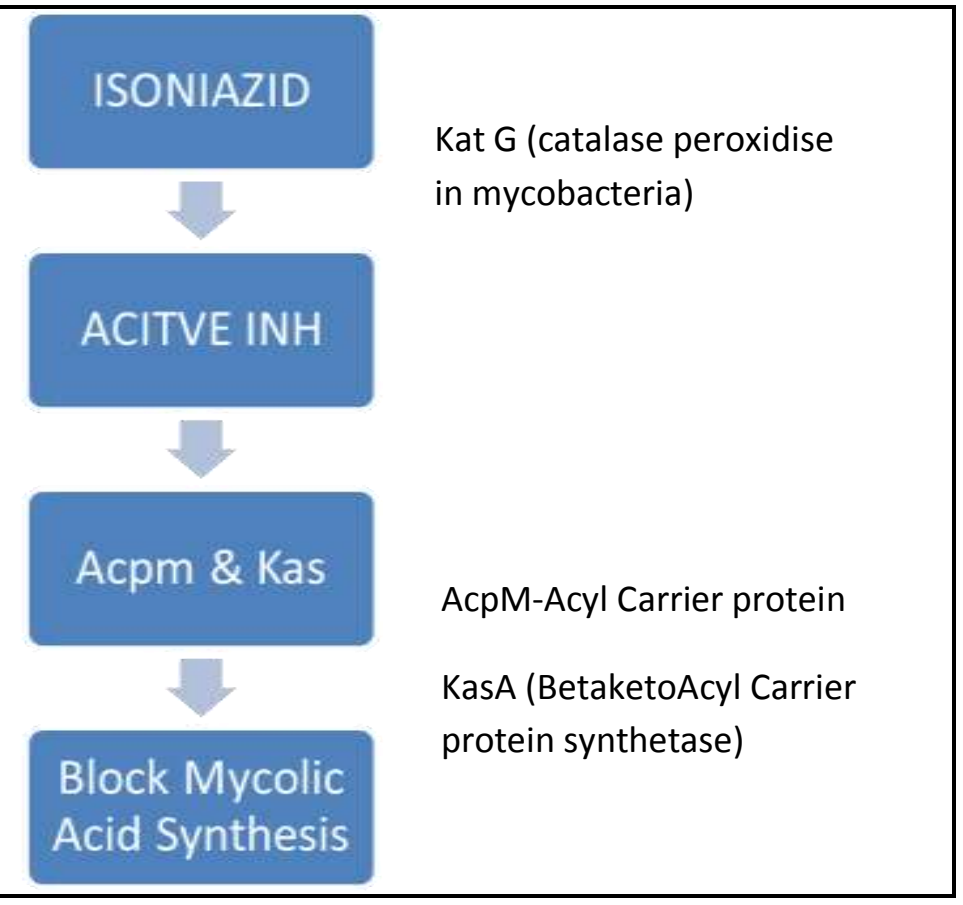

Fig.2. Mechanism of action of anti- tuberculin drug

As we know that anti-tubercular drugs plays a very important role in today's scenario. So it's necessary to perform the various analytical methods and bioanalytical methods on them. According to literature review of last few years there are so many precise and practical analytical methods are used for the fast qualitative analysis of pharmaceutical active substances.

In 1992, Shah Y et. al. a liquid chromatographic procedure for the analysis of Rifampicin and Isoniazid in pharmaceutical dosage forms utilizing reverse phase chromatography was developed. Isolation of analytes was carried out under isocratic conditions with an octadecylsilane column and an aqueous mobile phase containing methanol (75\%) and 0.02M Disodium Hydrogen Orthophosphate (25\%) with pH 4.5 adjusted with orthophosphoric acid. The detection was done at $254 \mathrm{~nm}^{20}$.

In 2002, Espinosa-Mansilla A et. al., the simultaneous determination of the antitubercular drugs rifampicin, pyrazinamide, isoniazid and the acetylisoniazid metabolite has been accomplished by LC, using a C-18 analytical column. The chromatographic method uses a gradient flow in three steps, in conjunction with a programmed diode array photometric detection. In a $0.02 \mathrm{M}$ potassium dihydrogen phosphate $\mathrm{pH} 7.0$ buffer, a $5 \%(\mathrm{v} / \mathrm{v})$ content of methanol for $3.4 \mathrm{~min}$, and a $75 \%(\mathrm{v} / \mathrm{v})$ content of methanol for 4 min were used. At 4.5 min, the wavelength value of detection was changed from 254 to $475 \mathrm{~nm}$. Creatinine, acetylisoniazid, isoniazid and pyrazinamide were eluted in the first $4.5 \mathrm{~min}$ and rifampicin before $8 \mathrm{~min}$. The method has been satisfactorily applied to the determination of the drugs in urine samples and in pharmaceuticals. The proposed LC method is simple, and a short time, less than 8 min is necessary for compounds elution ${ }^{21}$.

In 2002, Naidong $W$ et. al. demonstrated a novel approach of eliminating these two steps in 96-well SPE by using normal-phase LC/MS/MS methods with low aqueous/high organic mobile phases, which consisted of 70-95\% organic solvent, 5-30\% water, and small amount of volatile acid or buffer. While the commonly used SPE elution solvents i.e. acetonitrile and methanol have stronger elution strength than a mobile phase on reversed-phase chromatography, they are weaker elution solvents than a mobile phase for normalphase LC/MS/MS and therefore can be injected directly. Analytical methods for a range of polar pharmaceutical compounds, namely, omeprazole, metoprolol, fexofenadine, pseudoephedrine as well as rifampin and its metabolite 25-desacetyl-rifampin, in biological fluids, were developed and optimized based on the foregoing principles ${ }^{22}$.

In 2003, Mohan B et. al, observed that the requirements of theoretical plates listed in the given method were met for rifampcin, but not for isoniazid and pyrazinamide, even on columns of different makes. The resolving power of the method was also dependent upon makes of the column. On two of the three columns of 
the three tested, it was able to resolve most degradation products, except rifampicin $\mathrm{N}$-oxide and 25desacetylrifampicin, which were overlapping. The method was modified and an overall satisfactory resolution for all components was obtained by changing the buffer: organic modifier ratio of solution $\mathrm{B}$ in the gradient from 4:55 to $55: 45$ and decreasing the flow rate from 1.5 to $1.0 \mathrm{ml} / \mathrm{min}$, keeping all other conditions constant ${ }^{23}$.

In 2004, Hemanth Kumar AK et. al., developed a HPLC method for the determination of RMP and DRMP in plasma and urine. Separation in both was achieved by reverse phase chromatography on a C18 column with a mobile phase composition of $0.05 \mathrm{M}$ phosphate buffer: acetonitrile $(55: 45 \mathrm{v} / \mathrm{v})$ at $254 \mathrm{~nm}$. The retention times of DRMP, RMP and RPN, the internal standard was 2.9, 4.8 and 10.5 min respectively. The assay was linear from 0.25 to $15.0 \mu \mathrm{g} \mathrm{ml}^{-1}$ for urine. Both intra-day and inter-day accuracy and precision data showed good reproducibility ${ }^{24}$.

In 2007, Song SH et. al. described a method that can rapidly and simultaneously measure the blood concentration of four anti-tuberculosis drugs i.e. isonizid, rifampicin, pyrazinamide and ethambutol and two major metabolic rations like acetylisoniazid/isoniazid and 25-desacetylrifampicin/rifampicin using highperformance liquid chromatography/tandem mass spectrometry (HPLC/MS/MS). A C18 reversed-phase column and gradients of methanol in $0.3 \%$ formic acid and water were used for HPLC separation. The drug concentrations were determined by multiple reactions monitoring in positive ion mode and the assay performance was evaluated. The preparation of 20 samples including two steps of deproteinization with $50 \%$ and $100 \%$ methanol was performed within $20 \mathrm{~min}$ and chromatographic separation was achieved within 4 $\mathrm{min} / \mathrm{sample}$. Interassay calibration variability data obtained over concentrations of $0-8 \mathrm{microg} / \mathrm{mL}$ for isoniazid and ethambutol and 0-80 microg/mL for rifampicin and pyrazinamide showed a linear and reproducible curve. Within-run and between-run imprecision were $1.9-5.5 \%$ and 3.5-10.5\% and the lower limits of detection and quantification were $0.01-0.5$ microg/mL and 0.05-1.0 microg. $\mathrm{mL}$, respectively ${ }^{25}$.

In 2007, Patel PM et. al. developed a method for determination of Rabeprazole in pharmaceutical bulk dosage form. The method was based on the formation of ion-pair complexes of the drug with four dyes, viz. bromo thymol blue, bromocresol green, bromophenol blue and bromocresol purple in acidic buffer solutions followed by their extraction in chloroform. The absorbance of the organic layer was measured at its respective wavelength of maximum absorbance against the corresponding reagent blank. The method has been statistically evaluated and was found to be precise and accurate. Phosphate buffer of $\mathrm{pH} 2$ and bromocresol green dye gave maximum absorbance of Rabeprazole at $454 \mathrm{~nm}^{26}$.

In 2009, Dhal SK et. al. developed a method for simultaneous determination of pyridoxine hydrochloride, isoniazid, pyrazinamide and rifampicin in a tablet dosage form. Chromatographic analysis was performed on a $250 \times 4.6 \mathrm{~mm}$ I.D. C18 column packed with $5 \mathrm{~mm}$ in size particles applying gradient elution with a mobile phase composed of acetonitrile and $15 \mathrm{mmol} / \mathrm{L}$ potassium dihydrogen phosphate buffer of $\mathrm{pH}$ adjusted to $4.0 \pm 0.1$ with 0 -phosphoric acid. The ratio was $11: 89 \mathrm{v} / \mathrm{v}$ for the initial $4.5 \mathrm{~min}$, and then it was maintained at 50:50 v/v; the flow rate was $1 \mathrm{~mL} / \mathrm{min}$. UV detection was performed at $235 \mathrm{~nm}$. The total run time was $20 \mathrm{~min}$. Retention times for pyridoxine hydrochloride, isoniazid, pyrazinamide and rifampicin were 3.687, 4.113, 5.041 and $12.829 \mathrm{~min}$, respectively. Limits of detection were $0.043,0.063,0.036$ and $0.059 \mu \mathrm{g} / \mathrm{mL}$ and limits of quantification were $0.13,0.19,0.11$ and $0.18 \mu \mathrm{g} / \mathrm{mL}$ for pyridoxine hydrochloride, isoniazid, pyrazinamide and rifampicin respectively ${ }^{27}$.

In 2010, Mulabagal V, et. al., developed an ultrafiltration-liquid chromatography/mass spectrometry (UF-LC/MS) ligand based binding assay and an LC/MS based functional assay for Mycobacterium tuberculosis shikimate kinase (MtSK) were developed. Compounds $1,2,3$ and 4 were tested for MtSK $(1 \mu \mathrm{M})$ at a concentration of $1 \mu \mathrm{M}$. In order to evalutate the MtSk inhibitory activity, compounds 1-4 were tested at concentrations ranging from 0.05 to $1 \mu \mathrm{M}$ and the enzymatic activity was assessed by quantifying shikimate-3phosphate by LC/MS after $60 \mathrm{~min}$ incubation with $2 \mathrm{mM}$ shikimic acid as a substrate. The $\mathrm{EC}_{50}$ values of compounds $1,2,3$ and 4 were $0.30,0.24,0.07$ and $0.18 \mu \mathrm{M}$, respectively. The ligands and the S3P were analyzed using positive and negative electrospray LC/MS, respectively. The calibration curve for S3P was prepared with concentrations ranging from 4 to $125 \mu \mathrm{g} / \mathrm{mL}$, and the lower detection limit (LOD) of S3P was identified as $1.95 \mu \mathrm{g} / \mathrm{mL}^{28}$.

In 2010, Zhou Z et. al., developed a method for the simultaneous determination of pyrazinamide (PZA), isoniazid (INH), rifampicin (RFP) and acetylisoniazid (AcINH) in human plasma. Separation was performed on a Max-RP $\mathrm{C}_{12}$ column using gradient elution and a flow-rate program. The mobile phase was methanol- 
acetonitrile-buffer $(20 \mathrm{mM}$ of heptanesulfonic acid sodium, $\mathrm{pH} 2.5)$ with a ratio of 10:8:82 (v/v/v) at the initial phase. All calibration curves had good linearity $\left(\mathrm{r}^{2}>0.99\right)$ between the test ranges. The intra-and inter-day precision was less than $8.8 \%$ in good accuracy $(<15 \%)$. The limit of detection with a signal-to-noise $(\mathrm{S} / \mathrm{N})$ of 3 was $0.014,0.009,0.023$ and $0.054 \mu \mathrm{g} / \mathrm{mL}$ for PZA, AcINH, INH and RFP, respectively ${ }^{29}$.

In 2012, Bhandari $R$. et.al, developed a reverse phase high performance liquid chromatography method for quantitative determination of isoniazid (INH) in plasma, brain, liver and kidney samples and in solid lipid nanoparticles (SLNs). Isoniazid was analyzed by using a reverse phase column (Waters, Symmetry shield RP$18,4.6 \mathrm{~mm} \mathrm{X} 150 \mathrm{~cm}, 5$ microns), with mobile phase consisting of $0.1 \mathrm{M}$ phosphate buffer, $\mathrm{pH} 5$ (pH adjusted with ortho phosphoric acid) and methanol and the detection was made at $254 \mathrm{~nm}$ using Photo Diode Array detector at a temperature of $30^{\circ} \mathrm{C}$ (sample $4^{\circ} \mathrm{C}$ ). The retention time for INH was around 3.5 minutes. The calibration curves were linear $\left(\mathrm{r}^{2}=0.9998\right)$ over a concentration range from $250 \mathrm{ng}$ to $25,000 \mathrm{ng} / \mathrm{mL}$. Limit of detection was $150 \mathrm{ng} / \mathrm{mL}$ and the limit of quantitation was $200 \mathrm{ng} / \mathrm{mL}$ for plasma and tissue homogenates. Intra and inter-day variability's (RSD) for extraction of INH from plasma and other tissue homogenates were less than $5 \%$ and accuracy was $\pm 5 \%$. The results established selectivity and suitability of the method for pharmacokinetic studies of INH for INH SLNs ${ }^{30}$.

In 2012, Siddhartha TS et. al., developed a HPLC method for the determination of rifampicin (RIF) by UV detection in human plasma. Rifampicin was extracted from plasma utilizing liquid-liquid extraction process using a 70:30\% v/v mixture of t-butyl methyl and dichloromethane. Hydrochlorothiazide (HCTZ) was used as internal standard. Both RIF and HCTZ were eluted under isocratic mode using a $150 \mathrm{X} 4$. $6 \mathrm{~mm}$ i.d., $5 \mu \mathrm{m}$ Phenomenex ODS 2 C18 coloumn. A mixture of 40:60\% v/v acetonitrile and 10mM potassium dihydrogen phosphate was used as mobile phase at a flow rate of $1.0 \mathrm{ml} / \mathrm{min}$. The retention times for RIF and HCTZ were 6.80 and 2.56 minutes, respectively. The method showed good linearity in the range of 0.31 to $25.48 \mu \mathrm{g} / \mathrm{mL}$. The recovery of rifampicin was $90.07 \%$ with a CV of $3.26 \%$ and recovery of internal standard was $91.24 \%$ with a $\mathrm{CV}$ of $2.31 \%$. A rapid, sensitive, simple and cost effective method for the estimation of rifampicin in human plasma was developed ${ }^{31}$.

In 2012, Shewiyo DH et. al., developed a new RP-HPTLC method for the separation of pyrazinamide, isoniazid, rifampicin and ethambutol in a four fixed-dose combination tablet formulation. It is a single method with two steps in which after plate development pyrazinamide, isoniazid and rifampicin are detected at an UV wavelength of $280 \mathrm{~nm}$. Then ethambutol is derivatized and detected at a VIS wavelength of $450 \mathrm{~nm}$. Methanol, ethanol and propan-1-ol were evaluated modifiers to form alcohol-water mobile phases. Systematic optimization of the composition of each alcohol in the mobile phase was carried out using the window diagramming concept to obtain the best separation. Examination of the Rf distribution of the separated compounds showed that separation of the compounds with the mobile phase containing ethanol at the optimal fraction was almost situated within the optimal Rf-values region of 0.20-0.80. Therefore, ethanol was selected as organic modifier and the optimal mobile phase composition was found to be ethanol, water, glacial acetic acid (>99\% acetic acid) and 37\% ammonium solution (70/30/5/1, v/v/v/v). The method is new, quick and cheap compared to the actual method in the International Pharmacopoeia for the assay of the 4FDC tablets, which involves the use of two separate HPLC methods ${ }^{32}$.

In 2013, Siddhartha TS et.al., developed a extraction process which involved a liquid-liquid extraction using 70:30 \% v/v mixture of t-butyl methyl ether and dichloromethane. Both pyrazinamide and the internal standard were eluted under isocratic mode using a $150 \mathrm{X} 4.6 \mathrm{~mm}$ i.d., $5 \mu \mathrm{m}$ Phenomenex ODS $2 \mathrm{C}_{18}$ column. The mobile phase was composed of a mixture of $15: 85 \% \mathrm{v} / \mathrm{v}$ methanol and $\mathrm{O} \mathrm{mM}$ potassium dihydrogen phosphate at a flow rate of $1.0 \mathrm{ml} / \mathrm{min}$. The wavelength of detection was $268 \mathrm{~nm}$. The injection volume was $20 \mu \mathrm{L}$. The runtime of the method was $8 \mathrm{~min}$. The method showed good linearity in the range of $1.02-50.23 \mu \mathrm{g} / \mathrm{mL}$. The overall recovery of pyrazinamide was $27.21 \%$ with a $\mathrm{CV}$ of $2.71 \%$ and recovery of internal standard was $83.34 \%$ with a CV of $4.38 \%$.

In 2014, Shah UM, et. al., used methanol and distilled water as diluent. The wavelength selected for the analysis was $262 \mathrm{~nm}, 338 \mathrm{~nm}$ and $477 \mathrm{~nm}$ for INH, PIPE and RIFA respectively. The second RP-HPLC method has been developed using Acetonitrile as diluent. Sucessful separation of drugs was achieved on LC18 $100 \mathrm{~A}^{\circ}$ column $(250 \times 4.6 \mathrm{~mm}, 5 \mu)$ using 0.01M Sodium Dihydrogen Orthophosphate, pH 6.5 and acetonitrile (40:60, $\% \mathrm{v} / \mathrm{v})$ as mobile phase with flow rate of $0.9 \mathrm{~mL} / \mathrm{min}$. The wavelength of detection was $282 \mathrm{~nm}$. Validated of developed methods was done according to ICH Q2 (R1) guidelines. Calibration curve was linear over the concentration range of $12-34.5 \mu \mathrm{g} / \mathrm{mL}$ (INH), $8-23 \mu \mathrm{g} / \mathrm{mL}$ (RIFA) and 0.4-1.15 $\mu \mathrm{g} / \mathrm{mL}$ (PIPE) respectively or 
absorption correction method and 30-330 $\mu \mathrm{g} / \mathrm{mL}$ (INH), $20-220 \mu \mathrm{g} / \mathrm{mL}$ (RIFA) and 1-11 $\mu \mathrm{g} / \mathrm{mL}$ (PIPE) for RPHPLC method with $\mathrm{r}^{2}$ value greater than 0.995 . Accuracy of methods was determined by recovery studies and it was found to be 98 to $102 \%$. The \% RSD values for all the validation parameters were less than $2.0 \%$ for both the methods ${ }^{34}$.

In 2015, Bajetto L et.al., extracted Ethambutol, isoniazid, pyrazinamide and rifampicin from plasma and PBMCs using two separate and optimized procedures; analysis was performed using UPLC coupled with a mass-mass detector system (UPLC-MS-MS). Antitubercular levels in patients were assayed at the end of the dosing interval and $2 \mathrm{~h}$ post-dose. The method was accurate and precise. Recovery and the matrix effect were reproducible. While rifampicin intracellular concentrations were similar to plasma values isoniazid and pyrazinamide intracellular concentrations were lower than plasma values and ethambutol intracellular concentration were significantly higher than plasma values ${ }^{35}$.

In 2015, Sturekenboom MG, et. al., developed a LC-MS/MS method for the quantification of isoniazid, pyrazinamide and ethambutol. Stable isotope-labelled isoniazid-D4 and ethambutol was investigated and proved low. Therefore, sample preparation using ultrafiltration could be applied, resulting in linear calibration curves in the range of $0.2-8 \mathrm{mg} / \mathrm{L}$ for isoniazid and ethambutol and $2-80 \mathrm{mg} / \mathrm{L}$ for pyrazinamide. The method was validated according to the guidelines of the FDA. A fast, simple and reliable LC-MS/MS method has been developed for the simultaneous determination of isoniazid, pyrazinamide and ethambutol in human serum for therapeutic drug monitoring and pharmacokinetic studies ${ }^{36}$.

In 2015, Chellini PR, et. al., developed an HPLC-diode array detector method for the determination of RIF, INH, PYZ, and EMB in fixed dose combination tablets. Chromatographic experiments were performed on an Agilent 1200 HPLC system, and the separation was carried out on Purospher STAR RP 18e (250X4.6 mm id, $5 \mu \mathrm{M}$, Merck) analytical column. Gradient elution was carried out with a mobile phase of $20 \mathrm{mM}$ monobasic sodium phosphate buffer with $0.2 \%$ triethylamine $(\mathrm{pH} 7.0)$ and acetonitrile at a flow rate of $1.5 \mathrm{~mL} / \mathrm{min}$. The total run time was $12 \mathrm{~min}$, and the re-equilibration at was $5 \mathrm{~min}$. EMB detection was performed at $210 \mathrm{~nm}$, and RIF, INH and PYZ were detected at $238 \mathrm{~nm}$, using a DAD. The method proved to be specific, linear $\left(\mathrm{r}^{2}>0.99\right)$, precise $(\mathrm{RSD}<2 \%)$, accurate, and robust and may be applied to the $\mathrm{QC}$ analysis of pharmaceutical formulations ${ }^{37}$.

In 2015, Prasanthi B, et. al., developed a rapid, simple, sensitive and cost effective stability indication high performance liquid chromatographic method for the simultaneous determination of rifampicin, isoniazid and pyrazinamide in human plasma. The three drugs were eluted under isocratic mode using a $250 \mathrm{X} 4.0 \mathrm{~mm}$ id, $5 \mu \mathrm{m}$ Phenomenex ODS 2 C18 column. The mobile phase was composed of a mixture of acetonitrile, methanol and water in the ration of 30:5:65 (v/v, pH adjusted to 5.2) at flow rate of $1.0 \mathrm{~mL} / \mathrm{min}$. The limits of detection and quantification for rifampicin were 0.13 and $0.4 \mu \mathrm{g} / \mathrm{mL}$, for isoniazid- 0.6 and $1.8 \mu \mathrm{g} / \mathrm{mL}$; and pyrazinamide 0.5 and $1.6 \mu \mathrm{g} / \mathrm{mL}$, respectively. The method can be successfully applied for pharmacokinetic, bioavailability or bioequivalence studies of rifampicin, isoniazid and pyrazinamide combination in human subjects ${ }^{38}$.

In 2017, Hakkimane SS, et. al., used isocratic elution with 10 minutes runtime on a C18 Luna, 5I1/4, $100 \AA$, $150 \mathrm{~mm}$ column, methanol, and water as mobile phase with detection wavelength at $268 \mathrm{~nm}$. INH nanoformulations were prepared by double emulsion solvent evaporation technique. Quantitative analysis of encapsulated drug was estimated via developed RP-HPLC method. Simultaneous estimation for the two drugs was carried out by gradient elution. All chromatographic separation and estimations were obtained on Shimandzu HPLC system ${ }^{39}$.

In 2017, Mishra P, et. al., developed a direct injection liquid chromatographic method for the determination of pyrazinamide in pharmaceutical formulation. The method includes a micellar mobile phase containing $0.15 \mathrm{M}$ sodium dodecyl sulphate and $1 \%$ butanol (v/v) buffered at $\mathrm{pH} 3$, a Princeton SPHER-100 C18 column $(250 X 4.6 \mathrm{~mm}, 5 \mu \mathrm{m}$ particle size) and UV detection was set at $269 \mathrm{~nm}$. The micellar liquid chromatography (MLC) method is rapid, precise, sensitive and robust. In this method pharmaceutical samples were directly injected to the column without pre-treatment step. Under all these conditions, method has very short analysis time of $3.2 \mathrm{~min}$, linearity ( $r>0.998$ ), limit of detection and limit of quantification is $1.4,36.5$ $\mathrm{ng} / \mathrm{ml}$ respectively; intra and inter-day precision (RSD\%) were 1.5 , overall recovery in pharmaceutical formulation is $99.4 \%, 69.5 \%, 81.25 \%, 87.9 \%$. The method is suitable for routine quality control analysis. This chromatographic techniques, MLC has the advantage of avoiding sample extraction step from matrices, thus reduces the time of analysis ${ }^{40}$. 
In 2017, Hermawan D, et. al., developed a simple high performance liquid chromatography method for the analysis of miconazole, an antifungal drug in powder sample. The optimized HPLC system using C8 column was achieved using mobile phase composition containing methanol: water $(85: 15, \mathrm{v} / \mathrm{v})$, a flow rate of $0.8 \mathrm{~mL} / \mathrm{min}$, and UV detection at $220 \mathrm{~nm}$. The calibration graph was linear in the range from $10-50 \mathrm{mg} / \mathrm{L}$ with $\mathrm{r}^{2}$ of 0.9983 . The limit of detection (LOD) and limit of quantitation (LOQ) obtained were $2.24 \mathrm{mg} / \mathrm{L}$ and $7.47 \mathrm{mg} / \mathrm{L}$, respectively. The present HPLC method is applicable for the determination of $\mathrm{m}$ HPLC method provides short analysis time, high reproducibility and high sensitivity ${ }^{41}$.

In 2018, Khatak S, et. al., developed a new simple, rapid and sensitive reversed-phase highperformance liquid chromatography method as per International Conference on Harmonization guidelines, Q2R1, for simultaneous estimation of isoniazid, pyrazinamide and rifampicin in solid lipid nanoparticles. Separation was achieved on a $250 X 4.6 \mathrm{~mm}, 5 \mu \mathrm{m}, \mathrm{C} 18$ column using a linear gradient flow rate of $1.5 \mathrm{ml} / \mathrm{min}$. Isoniazid, pyrazinamide and rifampicin were identified based on their retention times as compared to standards and confirmed with characteristic spectra on a spectrophotometer at $238 \mathrm{~nm}$ and eluted at 3.787, 4.173 and $11.273 \mathrm{~min}$, respectively, achieved within $20 \mathrm{~min}$. This method was linear, precise with \%RSD values of $0.18 \%$ for isoniazid, $0.15 \%$ for pyrazinamide and $0.47 \%$ for rifampicin, accurate with mean recovery yields of $101.312 \%$ for isoniazid, $99.910 \%$ for pyrazinamide and $99.767 \%$ for rifampicin and selective over the concentration range of $10-15 \%$ for all the three drugs. This method is suitable due to its simplicity and accuracy for routine quality control and stability analysis of Antitubercular drugs-loaded solid lipid nanopaticles ${ }^{42}$.

In 2018, Le Thi Luven TM, et. al., described a method that can rapidly and simultaneously measure the plasma concentrations of four anti-tuberculosis drugs (isoniazid, rifampicin, pyrazinamide and ethambutol) and one major metabolite (acetylisoniazid) using high-performance liquid chromatography/tandem mass spectrometry (HPLC/MS/MS). To adjust for degradation and losses during sample preparation, Diltiazem hydrochloride was used as an internal standard. Samples were prepared by using protein precipitation with methanol. Four drugs and one metabolite were simultaneously separated by using the high-performance liquid chromatography system with Gemini C18 column and mobile phase consisting of $\mathrm{MeOH}$ and Ammonium Acetate $5 \mathrm{mM}, \mathrm{pH}$ 3.5. The method was found to have high selectivity. Precision estimated by the coefficient of variation was $<15 \%$ for all drugs. The linear range of the calibration curves for PZA $1.0-100 \mu \mathrm{g} / \mathrm{mL}$; RIF 0.2$20 \mu \mathrm{g} / \mathrm{mL}$; INH $0.1-10 \mu \mathrm{g} / \mathrm{mL}$; AcINH $0.1-10 \mu \mathrm{g} / \mathrm{mL}$ and EMB $20-5000 \mathrm{ng} / \mathrm{mL}$. The results of validation for selectivity/specificity, precision, accuracy, linearity, limit of quantification, recovery, and stability show that the method meets the requirements of a bioanalytical method. Our method may serve well for routine therapeutic monitoring of the first-line anti-TB drugs in patient plasma ${ }^{43}$.

In 2018, Luciani-Giacobbe LC, et. al., developed a simple and selective reversed phase HPLC-UV method for rifampicin and isoniazid quantification in human plasma. The method consisted of drug extraction with trichloroacetic acid and organic solvent followed by derivatization of isoniazid. Using an isocratic mode, rifampicin was analyzed on a C18 $(250 \mathrm{X} 4.6 \mathrm{~mm}, 5 \mu \mathrm{m})$ column at $339 \mathrm{~nm}$, while isoniazid was analyzed on a C8 $(250 \mathrm{X} 4.6 \mathrm{~mm}, 5 \mu \mathrm{m})$ column at $273 \mathrm{~nm}$. All validation parameters fulfilled the FDA requirements, as the method was accurate, precise and linear from 0.31 to $37.80 \mu \mathrm{g} / \mathrm{mL}$ of isoniazid. The samples remained stable during the usual processing and analysis times and also during the two freeze/thaw cycles. The recovery of both analytes was reproducible in the range of $97.3-99.6 \%$ of rifampicin and $89.8-96.6 \%$ of isoniazid. The low volume of plasma necessary for the quantification of the samples $(750 \mu \mathrm{L}$ in total) and the low limit of quantification $(0.31 \mu \mathrm{g} / \mathrm{mL}$ for rifampicin and $0.89 \mu \mathrm{g} / \mathrm{mL}$ for isoniazid) made this method useful for carrying out pharmacokinetic tests both in humans or animal models. In addition, the method can be successfully applied for bioavailability studies or drug monitoring in tuberculosis treatment ${ }^{44}$.

In 2018, Gao S, et. al., developed a simple and sensitive method based on liquid chromatographytandem mass spectrometry (LC-MS/MS) and single protein precipitation for simultaneously quantifying of pyrazinamide, isoniazid, ethambutol, streptomycin and rifampicin in human plasma. Optimized chromatographic separation was achieved on a ZORBX SB-C18 column with heptafluorobutyric acid, an ionpair reagent, in the mobile phase at a flow rate of $0.3 \mathrm{~mL} / \mathrm{min}$. The mass detection was achieved using electrospray ionization in the positive ion mode with multiple reactions monitoring mode. The lower limit of quantification (LLOQ) and dynamic range of pyrazinamide, isoniazid, ethambutol, streptomycin and rifampicin were $200-4000 \mathrm{ng} / \mathrm{mL}, 80-2000 \mathrm{ng} / \mathrm{mL}, 0.2-1000 \mathrm{ng} / \mathrm{mL}, 2000-200000 \mathrm{ng} / \mathrm{mL}$ and $200-4000 \mathrm{ng} / \mathrm{mL}$, respectively. The inter-day and intra-day accuracy and precision were within $\pm 15.0 \%$ and less than $15 \%$. The 
method had been successfully applied to simultaneous determination of four first-line Anti-tuberculosis drugs in plasma from tuberculosis patients ${ }^{45}$.

In 2018, Mishra P, et. al., described the development of a micellar liquid chromatographic method to quantify isoniazid in urine samples. Extraction steps were avoided, making the procedure easy to handle and reducing the waste of toxic organic solvents. Isoniazid was eluted in less than 5 min without interference from other compounds of the urine using a mobile phase containing 0.15 SDS-12.5\% 1-propanol (v/v)- $\mathrm{Na}_{2} \mathrm{HPO}_{4} 0.01$ $\mathrm{M}$ buffered at $\mathrm{pH} 7$, running at $1 \mathrm{~mL} / \mathrm{min}$ under isocratic mode through a $\mathrm{C} 18$ column with the detection wavelength at $265 \mathrm{~nm}$. The method was validated by following the requirements of the guidelines on Bioanalytical Method Validation issued by the European Medicines Agency (EMA) in terms of selectivity, calibration curve $\left(\mathrm{r}^{2}=0.9998\right.$ in the calibration range $\left.0.03-10.0 \mu \mathrm{g} / \mathrm{mL}\right)$, limit of detection and quantification (10 and $30 \mathrm{ng} / \mathrm{mL}$ respectively), precision $(<16.0 \%)$, accuracy $(-0.9$ to $+8.5 \%)$, carry-over, matrix effect, and robustness. The developed method was applied to quantify isoniazid in urine samples of patients of an India hospital with good results. The method was found to be useful for routine analysis to check the amount of isoniazid in these patients and could be used its therapeutic monitoring ${ }^{46}$.

In 2018, Laila L, et.al., developed a selective, reproducibility, effective, sensitive, simple and fast HighPerformance Liquid Chromatography (HPLC) to analyze 25-Desacetyl Rifampicin (25-DR) in human urine which is from tuberculosis patient. The separation was performed by HPLC Agilent Technologies with column Agilent Eclipse XDB-C18 and a mobile phase of 65:35 v/v methanol: 0.01M sodium phosphate buffer pH 5.2, at $254 \mathrm{~nm}$ and flow rate of $0.8 \mathrm{ml} / \mathrm{min}$. The mean retention time was 3.016 minutes. The method was linear from $2-10 \mu \mathrm{g} / \mathrm{ml} 25-\mathrm{DR}$ with a correlation coefficient of 0.9978. Standard deviation, relative standard deviation and coefficient variation of $2,6,10 \mu \mathrm{g} / \mathrm{ml} 25$-DR were $0-0.0829,03.1752,0-0.0317 \%$, respectively. The recovery of $5,7,9 \mu \mathrm{g} / \mathrm{ml} 25$-DR was $80.8661,91.3480$ and $111.1457 \%$, respectively. Limit of detection (LOD) and quantification (LOQ) were 0.51 and $1.7 \mu \mathrm{g} / \mathrm{ml}$, respectively. The method has fulfilled the validity guidelines of the International Conference on Harmonization (ICH) bioanalytical method which includes parameters of specificity, linearity, precision, accuracy, LOD, LOQ. The developed method is suitable for pharmacokinetic analysis of various concentrations of $25-\mathrm{DR}$ in human urine ${ }^{47}$.

In 2018, Khatak S, et. al., developed a rapid, simple, sensitive and cost effective stability indicating high performance liquid chromatographic method for the simultaneous determination of rifampicin, isoniazid, and pyrazinamide in human plasma. The three drugs were eluted under isocratic mode using a 250X4.0 mm i.d., $5 \mu \mathrm{m}$ Phenomenex ODS $2 \mathrm{C} 18$ column. The mobile phase was composed of a mixture of acetonitrile, methanol and water in the ration of 30:5:65 (v/v, pH adjusted to 5.2) at a flow rate of $1.0 \mathrm{~mL} / \mathrm{min}$. The limit of detection and quantification for rifampicin were 0.13 and $0.4 \mu \mathrm{g} / \mathrm{mL}$, for isoniazid- 0.6 and $1.8 \mu \mathrm{g} / \mathrm{mL}$; and for pyrazinamide- 0.5 and $1.6 \mu \mathrm{g} / \mathrm{mL}$, respectively. The method can be successfully applied for pharmacokinetic, bioavailability or bioequivalence studies of rifampicin, isoniazid and pyrazinamide combination in human subjects $^{48}$.

In 2019, Shah P, et. al., developed a accurate, precise and robust isocratic HPLC method for simultaneous determination of Rifampicin and Ofloxacin. The chromatographic separation was carried out on Kinetex C18, 100 A Phenomenex column with a mixture of $0.03 \mathrm{M}$ Potassium dihydrogen phosphate buffer $\mathrm{pH}$ 3.0: Acetonitrile $(55: 45)$ as mobile phase at $230 \mathrm{~nm}$. The retention times were 2.91 and $4.87 \mathrm{~min}$ for Ofloxacin and Rifampicin, respectively. Calibration plots were linear over the concentration range $1-5$ and $2-10 \mu \mathrm{g} / \mathrm{mL}$ for Rifampicin and Ofloxacin, respectively. The method was validated for linearity, sensitivity accuracy, precision, and robustness. Percent recoveries were found to be close to $100 \%$ with low variability. Fractional factorial design with four factors was chosen for robustness testing. The volume of acetonitrile and flow rate showed significant effect on retention factor of both the drugs and asymmetry factor of ofloxacin. The method may be adopted for routine analysis at industry ${ }^{49}$.

In 2019, Temova Rakusa Z, et. al., developed a simple, fast and cost-effective LC-MS/MS method for quantification of rifampicin in human plasma. The plasma samples containing rifampicin and isotopically labelled internal standard rifampicin D8, were cleaned up using a Captiva ND lipids filtration plate. Chromatograph separation was achieved on an 1290 Infinity liquid chromatography coupled to 6460 Triple Quadrupole operated in positive mode on a core-shell Kinetex C18 column $(50 \times 2.1 \mathrm{~mm}, 2.6 \mu \mathrm{m})$ by gradient elution using $0.1 \%$ formic acid in water and acetonitrile as a mobile phase. The proposed method is the fastest method published by now, both in terms of sample preparation and chromatographic analysis (total run time $2.4 \mathrm{~min})$. Another key benefit is the outstanding sensitivity and wide analytical range $(5-40000 \mu \mathrm{g} / \mathrm{L})$ with good 
linearity, accuracy and precision. The method showed almost complete recovery (92\%) and absence of any significant matrix effect as demonstrated by uniform responses from QC samples prepared in blood plasma from 6 volunteers. The proposed method was successfully applied to rifampicin quantification in 340 patient's plasma samples, thus demonstrating its suitability for both therapeutic drug monitoring and pharmacokinetic analysis $^{50}$.

\section{Conclusion:}

This review focuses on introductory aspects of tuberculosis, symptoms, some newer analogues under investigation and various analytical, bioanalytical methods reported on antitubercular agents. This paper will definitely help graduate researcher working in analytical chemistry to define their direction in liquid chromatographic method development.

\section{References:}

1. Mason CM, Dobard E, Zhang P, Nelson S. Alcohol exacerbates murine pulmonary tuberculosis. Infection and immunity. 2004 May 1;72(5):2556-63.

2. Gawad J, Bonde C. Current affairs, future perspectives of tuberculosis and antitubercular agents. Indian Journal of Tuberculosis. 2018 Jan 1;65(1):15-22.

3. Hayward S, Harding RM, McShane H, Tanner R. Factors influencing the higher incidence of tuberculosis among migrants and ethnic minorities in the UK. F1000Research. 2018;7.

4. Bonde CG, Gaikwad NJ. Synthesis and preliminary evaluation of some pyrazine containing thiazolines and thiazolidinones as antimicrobial agents. Bioorganic \& medicinal chemistry. 2004 May 1;12(9):2151-61.

5. Makarov V, Manina G, Mikusova K, Möllmann U, Ryabova O, Saint-Joanis B, Dhar N, Pasca MR, Buroni S, Lucarelli AP, Milano A. Benzothiazinones kill Mycobacterium tuberculosis by blocking arabinan synthesis. Science. 2009 May 8;324(5928):801-4.

6. Gawad J, Bonde C. Decaprenyl-phosphoryl-ribose 2'-epimerase (DprE1): challenging target for antitubercular drug discovery. Chemistry Central Journal. 2018 Dec;12(1):72.

7. Neres J, Hartkoorn RC, Chiarelli LR, Gadupudi R, Pasca MR, Mori G, Venturelli A, Savina S, Makarov V, Kolly GS, Molteni E. 2-Carboxyquinoxalines kill Mycobacterium tuberculosis through noncovalent inhibition of DprE1. ACS chemical biology. 2014 Dec 9;10(3):705-14.

8. Neres J, Pojer F, Molteni E, Chiarelli LR, Dhar N, Boy-Röttger S, Buroni S, Fullam E, Degiacomi G, Lucarelli AP, Read RJ. Structural basis for benzothiazinone-mediated killing of Mycobacterium tuberculosis. Science translational medicine. 2012 Sep 5;4(150):150ra121-.

9. Tiwari RN, Bonde CG. LC, LC-MS/TOF, AND MSN STUDIES FOR THE SEPARATION, IDENTIFICATION, AND CHARACTERIZATION OF DEGRADATION PRODUCTS OF LINEZOLID. Journal of Liquid Chromatography \& Related Technologies. 2012 Jan 1;35(1):188-203.

10. Diel R, Loddenkemper R, Nienhaus A. Predictive value of interferon- $\gamma$ release assays and tuberculin skin testing for progression from latent TB infection to disease state. Chest. 2012 Jul 1;142(1):63-75.

11. Bonde CG, Peepliwal A, Gaikwad NJ. Synthesis and Antimycobacterial Activity of Azetidine-, Quinazoline-, and Triazolo-thiadiazole-containing Pyrazines. Archiv der Pharmazie: An International Journal Pharmaceutical and Medicinal Chemistry. 2010 Apr;343(4):228-36.

12. Dye C. Global epidemiology of tuberculosis. The Lancet. 2006 Mar 18;367(9514):938-40.

13. Gawad J, Bonde C. Design, synthesis and biological evaluation of some 2-(6-nitrobenzo [d] thiazol-2ylthio)-N-benzyl-N-(6-nitrobenzo [d] thiazol-2-yl) acetamide derivatives as selective DprE1 inhibitors. Synthetic Communications. 2019 Oct 18;49(20):2696-708.

14. Comas I, Gagneux S. The past and future of tuberculosis research. PLoS pathogens. 2009 Oct 26;5(10):e1000600.

15. Peepliwal A, Vyawahare SD, Bonde CG. A quantitative analysis of Zidovudine containing formulation by FT-IR and UV spectroscopy. Analytical Methods. 2010;2(11):1756-63.

16. Riccardi G, Pasca MR, Chiarelli LR, Manina G, Mattevi A, Binda C. The DprE1 enzyme, one of the most vulnerable targets of Mycobacterium tuberculosis. Applied microbiology and biotechnology. 2013 Oct 1;97(20):8841-8. 
17. Peepliwal A, Bonde CG, Bothara KG. A validated RP-HPLC method for quantitative determination of related impurities of ursodeoxycholic acid (API) by refractive index detection. Journal of pharmaceutical and biomedical analysis. 2011 Mar 25;54(4):845-9.

18. Gawad J, Bonde C. Synthesis, biological evaluation and molecular docking studies of 6-(4nitrophenoxy)-1 H-imidazo [4, 5-b] pyridine derivatives as novel antitubercular agents: future DprE1 inhibitors. Chemistry Central Journal. 2018 Dec;12(1):138.

19. Tiwari RN, Bonde CG, Bothara KG. IDENTIFICATION AND CHARACTERIZATION OF DEGRADATION PRODUCTS OF RALTEGRAVIR USING LC, LC-MS/TOF, AND MSN. Journal of Liquid Chromatography \& Related Technologies. 2013 Mar 1;36(8):1078-95.

20. Shah Y, Khanna S, Jindal KC, Dighe VS. Determination of rifampicin and isoniazid in pharmaceutical formulations by HPLC. Drug development and industrial pharmacy. 1992 Jan 1;18(14):1589-96.

21. Espinosa-Mansilla A, Acedo-Valenzuela MI, De La Peña AM, Cañada FC, López FS. Determination of antitubercular drugs in urine and pharmaceuticals by LC using a gradient flow combined with programmed diode array photometric detection. Talanta. 2002 Aug 23;58(2):273-80.

22. Naidong W, Shou WZ, Addison T, Maleki S, Jiang X. Liquid chromatography/tandem mass spectrometric bioanalysis using normal-phase columns with aqueous/organic mobile phases-a novel approach of eliminating evaporation and reconstitution steps in 96-well SPE. Rapid communications in mass spectrometry. 2002 Oct 30;16(20):1965-75.

23. Mohan B, Sharda N, Singh S. Evaluation of the recently reported USP gradient HPLC method for analysis of anti-tuberculosis drugs for its ability to resolve degradation products of rifampicin. Journal of pharmaceutical and biomedical analysis. 2003 Mar 10;31(3):607-12.

24. Hemanth Kumar AK, Chandra I, Geetha R, Silambu Chelvi K, Lalitha V, Prema G. A validated highperformance liquid chromatography method for the determination of rifampicin and desacetyl rifampicin in plasma and urine. Indian journal of pharmacology. 2004;36(4):231-3.

25. Song, S.H., Jun, S.H., Park, K.U., Yoon, Y., Lee, J.H., Kim, J.Q. and Song, J., 2007. Simultaneous determination of first-line anti-tuberculosis drugs and their major metabolic ratios by liquid chromatography/tandem mass spectrometry. Rapid Communications in Mass Spectrometry: An International Journal Devoted to the Rapid Dissemination of Up-to-the-Minute Research in Mass Spectrometry, 21(7), pp.1331-1338.

26. Patel MM, Bhuva SD, Patel MM. Proton pump inhibitors: recent developments in analytical methodologies. Reviews in Analytical Chemistry. 2015 Oct 1;34(1-2):29-43.

27. Dhal SK, Sharma R. Development and validation of RP-HPLC method for simultaneous determination of pyridoxine hydrochloride, isoniazid, pyrazinamide and rifampicin in pharmaceutical formulation. Chemia Analityczna. 2009 Jan 1;54(6):1487.

28. Mulabagal V, Calderón AI. Development of an ultrafiltration-liquid chromatography/mass spectrometry (UF-LC/MS) based ligand-binding assay and an LC/MS based functional assay for Mycobacterium tuberculosis shikimate kinase. Analytical chemistry. 2010 Apr 15;82(9):3616-21.

29. Zhou Z, Chen L, Liu P, Shen M, Zou F. Simultaneous determination of isoniazid, pyrazinamide, rifampicin and acetylisoniazid in human plasma by high-performance liquid chromatography. Analytical Sciences. 2010 Nov 10;26(11):1133-8.

30. Bhandari R, Kaur IP. A sensitive HPLC method for determination of isoniazid in rat plasma, brain, liver and kidney. J. Chromatogr. Sep. Tech. 2012 Jun;3:128.

31. Siddhartha TS, Prasanthi B, Santosh T, Ratna JV. Development and validation of high performance liquid chromatographic method for the determination of rifampicin in human plasma. Int $\mathrm{J}$ Pharm Pharm Sci. 2012 Dec;4(5):362-7.

32. Shewiyo DH, Kaale E, Risha PG, Dejaegher B, Smeyers-Verbeke J, Vander Heyden Y. Optimization of a reversed-phase-high-performance thin-layer chromatography method for the separation of isoniazid, ethambutol, rifampicin and pyrazinamide in fixed-dose combination antituberculosis tablets. Journal of Chromatography A. 2012 Oct 19;1260:232-8.

33. Siddhartha TS, Prasanthi B, Santosh T, Ratna JV. Development and validation of high performance liquid chromatographic method for the determination of pyrazinamide in human plasma. Journal of Pharmacy Research. 2013 Jan 1;7(1):33-8.

34. Shah UM, Jasani AN. UV spectrophotometric and RP-HPLC methods for simultaneous estimation of isoniazid, rifampicin and piperine in pharmaceutical dosage form. International Journal of Pharmacy and Pharmaceutical Sciences. 2014;6(10):27480. 
35. Baietto L, Calcagno A, Motta I, Baruffi K, Poretti V, Di Perri G, Bonora S, D'Avolio A. A UPLC-MSMS method for the simultaneous quantification of first-line antituberculars in plasma and in PBMCs. Journal of Antimicrobial Chemotherapy. 2015 Jun 11;70(9):2572-5.

36. Sturkenboom MG, van der Lijke H, Jongedijk EM, Kok WT, Greijdanus B, Uges DR, Alffenaar JW. Quantification of isoniazid, pyrazinamide and ethambutol in serum using liquid chromatographytandem mass spectrometry. J Appl Bioanal. 2015 Jul 15;1(3):89-98.

37. Chellini PR, Lages EB, Franco PH, Nogueira FH, César IC, Pianetti GA. Development and validation of an HPLC method for simultaneous determination of rifampicin, isoniazid, pyrazinamide, and ethambutol hydrochloride in pharmaceutical formulations. Journal of AOAC International. 2015 Sep 1;98(5):1234-9.

38. Prasanthi B, Ratna JV, Phani RC. Development and validation of RP-HPLC method for simultaneous estimation of rifampicin, isoniazid and pyrazinamide in human plasma. Journal of analytical chemistry. 2015 Aug 1;70(8):1015-22.

39. Hakkimane SS, Guru BR. Nano formulation analysis: analytical method development of isoniazid and simultaneous estimation of anti-tubercular drugs isoniazid and rifampicin by RP-HPLC. Asian J Pharm Clin Res. 2017 Jan 1;10(5):330-5.

40. Mishra P, Durgbanshi A, Pawar RP, Sharma G, Biswas P. Quality control of pyrazinamide in formulation using micellar liquid chromatography. Int. J. Pharm. Sci. Res. 2017 Nov 1;8(11):4637-44.

41. Hermawan D, Sulaeman U, Istiqomah A, Aboul-Enein HY. Development of high performance liquid chromatography method for miconazole analysis in powder sample. InIOP Conference Series: Materials Science and Engineering 2017 Feb (Vol. 172, No. 1, p. 012011). IOP Publishing.

42. Singh RM, Saini PK, Mathur SC, Singh GN, Lal B. Development and validation of a RP-HPLC method for estimation of montelukast sodium in bulk and in tablet dosage form. Indian journal of pharmaceutical sciences. 2010 Mar;72(2):235.

43. Li AC, Junga H, Shou WZ, Bryant MS, Jiang XY, Naidong W. Direct injection of solid-phase extraction eluents onto silica columns for the analysis of polar compounds isoniazid and cetirizine in plasma using hydrophilic interaction chromatography with tandem mass spectrometry. Rapid communications in mass spectrometry. 2004 Oct 15;18(19):2343-50.

44. Luciani-Giacobbe LC, Guzman ML, Manzo RH, Olivera ME. Validation of a simple isocratic HPLCUV method for rifampicin and isoniazid quantification in human plasma. Journal of Applied Pharmaceutical Science. 2018 Jul;8(07):093-9.

45. Gao S, Wang Z, Xie X, You C, Yang Y, Xi Y, Chen W. Rapid and sensitive method for simultaneous determination of first-line anti-tuberculosis drugs in human plasma by HPLC-MS/MS: Application to therapeutic drug monitoring. Tuberculosis. 2018 Mar 1;109:28-34.

46. Mishra P, Durgbanshi A, Pawar RP, Sharma G, Biswas P. Quality control of pyrazinamide in formulation using micellar liquid chromatography. Int. J. Pharm. Sci. Res. 2017 Nov 1;8(11):4637-44.

47. Laila L, Prasetyo BE. Optimization and validation of high-performance liquid chromatography method for analyzing 25-desacetyl rifampicin in human urine. InIOP Conference Series: Earth and Environmental Science 2018 Mar (Vol. 125, No. 1, p. 012221). IOP Publishing.

48. Singh RM, Saini PK, Mathur SC, Singh GN, Lal B. Development and validation of a RP-HPLC method for estimation of montelukast sodium in bulk and in tablet dosage form. Indian journal of pharmaceutical sciences. 2010 Mar;72(2):235.

49. Shah P, Pandya T, Gohel M, Thakkar V. Development and Validation of HPLC method for simultaneous estimation of Rifampicin and Ofloxacin using experimental design. Journal of Taibah University for Science. 2019 Dec 11;13(1):146-54.

50. Temova Rakuša Ž, Roškar R, Klančar Andrejc A, Trdan Lušin T, Faganeli N, Grabnar I, Mrhar A, Kristl A, Trontelj J. Fast and Simple LC-MS/MS Method for Rifampicin Quantification in Human Plasma. International journal of analytical chemistry. 2019;2019. 